\title{
Application of an indwelling vascular access port for intravenous administration in a repeated and intermittent dose toxicity study in rats
}

\author{
Junko Taketoh, Shun-ichiro Komatsu, Kenji Adachi, Ryo Takai and Kentaro Asanuma \\ Safety Assessment Department, Chugai Pharmaceutical Co., Ltd., 1-135 Komakado, Gotemba-shi, Shizuoka \\ 412-8513, Japan
}

(Received September 2, 2008; Accepted October 27, 2008)

\begin{abstract}
Totally implantable catheter animal models are considered useful for pharmacological and toxicological studies. In this report, we assessed the feasibility of using an indwelling vascular access port (VAP) in rats for long-term evaluation of repeated and intermittent dose toxicity studies. In Experiment 1 , the VAP devices were implanted in male and female rats and a saline solution administered intravenously via the posterior vena cava for 2 weeks $(4 \mathrm{ml} / \mathrm{kg}, 2 \mathrm{ml} / \mathrm{min}, 5$ times/week, 10 times total). General conditions, body weight and blood chemistry showed no toxicological changes compared with the rats in the non-implanted, non-treated group. Hematology changes such as transient increases in peripheral blood reticulocytes and eosinophils were noted post-implantation. In pathology, proliferation of the endothelium at the site of VAP implantation and perivascular inflammatory cell infiltration including eosinophils in lung were noted at the end of the treatment period. Moreover, we found that the lumbar area is more suitable for VAP implantation than the back of neck for young, still growing rats. Experiment 2 included a 1-month intravenous intermittent dose $(4 \mathrm{ml} / \mathrm{kg}, 2 \mathrm{ml} / \mathrm{min}, 1$ time/week, 5 times total $)$ toxicity study in VAP-implanted rats followed by a 1-month recovery period conducted under Good Laboratory Practice (GLP) regulations. The results suggested that an animal model with implanted VAP is useful for intermittent intravenous dosing of drugs. Moreover, VAP implantation in animals is expected to be extrapolated to use VAP in humans in clinical studies.
\end{abstract}

Key words: Rat, Vascular access port catheter, Intravenous administration, Intermittent dose, Toxicity study

\section{INTRODUCTION}

Intravenous administration of drugs to laboratory animals is important in pharmacological and toxicological evaluation of drugs. Rats and mice are commonly used animals because of the amount of historical data available, reasonable cost and easy handling. However, in chronic studies, sometimes extravasation is a problem with repeated intravenous administration into the tail vein (Groman and Reinhardt, 2004). Hence, various systems and techniques for continuous vascular access have been developed. Tethered infusion systems including a jacket/ harness (Gebhardt et al., 1997) and tail cuff (Cave et al., 1995; Wijk et al., 2000; Asanuma et al., 2006) are well used in rodents but require additional equipment (swivels, external catheters, lever arms, etc.) and enough space where these items set up. However, a totally implantable catheter-port system has been used in rabbits (PerryClark et al., 1991), monkeys (Wojnicki et al., 1994), dogs (Garner and Laks, 1985) and rats (Garner et al., 1988). A totally implantable catheter-port systems enables the animal to have complete freedom of movement and less stress and does not require extra space. These models are useful for preclinical examination of drugs requiring periodic intravenous administration and have flexibility for study design. Some studies using totally implantable catheters in rat models have been reported (Tesche et al., 2002; Wit et al., 2001; Wachtman et al., 2006). However, basic information such as clinical and/or pathological examination which needs toxicological study has not been reported. More precise toxicological information and better procedures are required in early development. To

Correspondence: Junko Taketoh (E-mail: taketojnk@chugai-pharm.co.jp) 


\section{J. Taketoh et al.}

improve the situation, we aim to provide a procedure and background data for a toxicity study in rats using intravenous administration via a totally implantable catheter-port system. In this report, vascular access ports catheter (vascular access port (VAP); Access Technologies, Norfolk Medical, Inc., Skokie, IL, USA) consisting of a silicone rubber septum (port) held in place by a rigid biocompatible polysulfone or titanium base and a catheter from port to injection site (Fig. 1) was used. The VAP is easily implantable and the subcutaneous location of the system is considered to minimize the risk of infection compared with external catheter systems. First, we conducted a validation study (Experiment 1: $4 \mathrm{ml} / \mathrm{kg}, 2 \mathrm{ml} / \mathrm{min}, 2$ weeks, 5 times/week for a total of 10 times) to determine whether the use of VAP-implanted rats (male and female) for a repeated dose toxicity study complied with Good Laboratory Practice (GLP) guidelines. Then, a 1-month intravenous intermittent dose toxicity study (Experiment 2: 4 $\mathrm{ml} / \mathrm{kg}, 2 \mathrm{ml} / \mathrm{min}, 1$ time/week for a total of 5 times) followed by a 1-month recovery period was conducted in a GLP environment.

\section{MATERIALS AND METHODS}

\section{Animals and housing conditions}

Six-week-old male and female rats (Crl:CD, SD) obtained from Charles River Laboratories Japan, Inc. (Kanagawa, Japan) were used in the study. The rats were housed one per cage and acclimatized in the animal facility for at least 1 week before use and were maintained in standard conditions (12-hr light/12-hr dark cycle, $22 \pm$ $2{ }^{\circ} \mathrm{C}, 55 \pm 20 \%$ relative humidity and $14-16$ air changes/ $\mathrm{hr}$ ventilation cycle). Animals were provided ad libitum access to a pellet rodent diet (CE-2, CLEA Japan, Inc.,

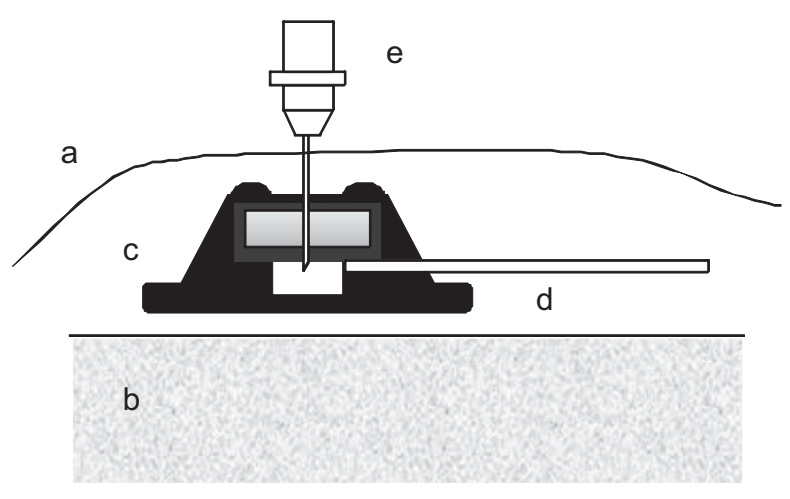

Fig. 1. Schema of the VAP system a, skin; b, fascia; c, VAP port; d, VAP catheter; e, Huber needle
Tokyo, Japan) and tap water via an automatic watering system. All procedures associated with this study were reviewed and approved by the Institutional Animal Care and Use Committee at Chugai Pharmaceutical Co., Ltd. (Tokyo, Japan). The study was conducted following principles stated in the Guide for the Care and Use Laboratory Animals, National Research Council, 1996.

\section{VAP catheter implantation and maintenance}

At the age of 7 weeks, rats were anesthetized with ketamine hydrochloride $(50 \mathrm{mg} / \mathrm{kg}$, i.p., Sankyo Yell Yakuhin Co., Ltd., Tokyo, Japan) and xylazine hydrochloride (5 $\mathrm{mg} / \mathrm{kg}$, i.p., Bayer, Co., Ltd., Tokyo, Japan) and implantation of the VAP (ROP-3H, polyurethane, 3 Fr.) was conducted under sterile conditions. Eye drop administration of chondroitin sodium sulfate (Santen Pharmaceutical Co., Ltd., Osaka, Japan) was performed to prevent ocular drying and thereby avoid procedure-related ophthalmological findings (Oliver et al., 1997). The inner thigh area and the back of the neck or the lumbar area where the port reservoir would be implanted were shaved, and then washed with $0.05 \%$ chlorhexidine gluconate solution (Dainippon Sumitomo Pharma Co., Ltd., Osaka, Japan) and ethanol swab. An incision was made in inner thigh area and femoral vein was isolated. The VAP port pre-filled with saline containing $100 \mathrm{IU} / \mathrm{ml}$ heparin sodium (Nipro Pharma Corp., Osaka, Japan) was implanted subcutaneously in the back of the neck (Experiment 1) or the lumbar area (Experiment 2). Then, the free end of the VAP catheter was tunneled subcutaneously from the VAP port site to an exit incision in the inner thigh area. The end of the catheter was inserted into a small incision on the femoral vein to a depth of $4.5 \mathrm{~cm}$. Catheter placement and patency were confirmed by freely aspirating blood. Incisions in the inner thigh area and the VAP port site were instilled with cefazolin sodium hydrate $(0.25 \mathrm{~g} / \mathrm{ml}$; Astellas Pharma Inc., Tokyo, Japan) before closure. In this study, the femoral vein (posterior vena cava) was selected as the cannulation route because the commonly used jugular vein has a risk of accidental introduction of the catheter tip into the right atrium. Moreover, it has been reported that cannulation of the femoral vein compared with the jugular vein prolongs catheter patency (Yang et al., 2005; Kaufman, 1980).

VAP maintenance included daily flushing of the port and catheter for the first 3 days after implantation and from then every 3 or 4 days until the end of the study. The maintenance process was as follows. The VAP port site was cleaned with $0.05 \%$ chlorhexidine gluconate solution and $70 \%$ ethanol swabs. A Huber point needle connected to a syringe was pushed firmly through the skin to reach 
Intravenous intermittent dose toxicity study using VAP in rats

the VAP port. In order to prevent coagulation, the VAP and catheter were flushed and displaced with saline containing heparin.

\section{Experiment design}

First, Experiment 1 was conducted as a validation study for 2 weeks to determine whether the VAP-implanted rats were used for a repeated dose toxicity study. After that, we conducted a GLP study for evaluation of some drug as Experiment 2 which was 1-month intravenous intermittent dose toxicity study followed by a 1-month recovery period. In Experiment 2, some changes not found for Experiment 1 were noted in control animals. Therefore, in this report, control animal data of Experiment 2 was reported only as VAP-implanted rat specific changes.

With both Experiment 1 and Experiment 2, general conditions were observed daily and body weight measured twice a week using an electronic balance (Shimadzu Co., Kyoto, Japan). At the end of each study, hematology examination, blood chemistry exanimation, necropsy, and histopathology were performed. The first dosing day was counted as Day 0 for both the Experiment 1 and Experiment 2 .

In Experiment 1, VAP implantation was successfully performed in 15 out of 19 males and 16 out of 18 females on Day -13. On the day before VAP implantation (Day -14) and 1 week after (Day -5), hematological examination was conducted in conscious animals. Two weeks after VAP implantation, a total of 4 animals ( 3 males and 1 female) were excluded from group allocation (refer to Table 1). Then other rats were assigned to groups (6 animals/sex) based on body weight. The remainder rats were transferred to another preliminary study, after which their data was no longer included in this report. VAP-implanted rats received saline (dosing volume, $4 \mathrm{ml} / \mathrm{kg}$; dosing speed, $2 \mathrm{ml} / \mathrm{min}$ ) by posterior vena cava via VAP for 2 weeks (5 times/week, 10 times total) and the results compared with the intact rats in the non-VAP-implantation and non-treatment group.

In Experiment 2, VAP implantations were performed on Day -14 through Day -11 with successful implantation in 87 out of 96 males and 87 out of 98 females. About two weeks after VAP implantation, a total of 19 animals (10 males and 9 females) out of successfully implanted animals were excluded from group allocation (see Table 1). Of the normal rats, 15 animals were assigned to a control group and the others divided into 3 test article-treatment groups based on body weight. Five animals of the control group animals were allocated to recovery. The control group received saline (dosing volume, $4 \mathrm{ml} / \mathrm{kg}$; dosing speed, $2 \mathrm{ml} / \mathrm{min}$ ) by posterior vena cava via VAP for 1 month (1 time/week, 5 times total) followed by a 1month recovery period of maintenance only.

\section{Hematology and blood chemistry examination}

Blood samples were collected from the jugular vein on

Table 1. VAP-implantation and post-implantation complications

\begin{tabular}{|c|c|c|c|c|}
\hline & \multicolumn{2}{|c|}{ Experiment $1^{\mathrm{a}}$} & \multicolumn{2}{|c|}{ Experiment $2^{\mathrm{b}}$} \\
\hline & $\begin{array}{c}\text { Male } \\
\mathrm{n}=19\end{array}$ & $\begin{array}{c}\text { Female } \\
\mathrm{n}=18\end{array}$ & $\begin{array}{c}\text { Male } \\
\mathrm{n}=96\end{array}$ & $\begin{array}{c}\text { Female } \\
\mathrm{n}=98\end{array}$ \\
\hline \multicolumn{5}{|l|}{ Implantation surgery } \\
\hline Death from surgical error & $3(16 \%)$ & $2(11 \%)$ & $3(3 \%)$ & $0(0 \%)$ \\
\hline Death from anesthesia & $1(5 \%)$ & $0(0 \%)$ & $4(4 \%)$ & $9(9 \%)$ \\
\hline Occlusion of VAP catheter & $0(0 \%)$ & $0(0 \%)$ & $2(2 \%)$ & $2(2 \%)$ \\
\hline Number of animals excluded on operation & $4(21 \%)$ & $2(11 \%)$ & $9(9 \%)$ & $11(11 \%)$ \\
\hline \multicolumn{5}{|l|}{ Post-implantation } \\
\hline Abnormality in general conditions & $0(0 \%)$ & $0(0 \%)$ & $2(2 \%)$ & $1(1 \%)$ \\
\hline Death from anesthesia at re-operation & $1(5 \%)$ & $0(0 \%)$ & $0(0 \%)$ & $0(0 \%)$ \\
\hline Open incision at the port site of VAP & $2(11 \%)$ & $0(0 \%)$ & $1(1 \%)$ & $1(1 \%)$ \\
\hline Difficulty of injection through VAP & $0(0 \%)$ & $0(0 \%)$ & $1(1 \%)$ & $0(0 \%)$ \\
\hline Suppressed body weight gain & $0(0 \%)$ & $0(0 \%)$ & $5(5 \%)$ & $4(4 \%)$ \\
\hline Ophthalmologic abnormality & $0(0 \%)$ & $0(0 \%)$ & $1(1 \%)$ & $3(3 \%)$ \\
\hline Low platelet count & $0(0 \%)$ & $1(6 \%)$ & $0(0 \%)$ & $0(0 \%)$ \\
\hline Number of animals excluded at post operation & $3(16 \%)$ & $1(6 \%)$ & $10(10 \%)$ & $9(9 \%)$ \\
\hline Total number of animals excluded & $7(37 \%)$ & $3(17 \%)$ & $19(20 \%)$ & $20(21 \%)$ \\
\hline
\end{tabular}

aVAP validation study; ${ }^{b} 1$-month intravenous intermittent toxicity study followed by a 1-month recovery period 
Days -14 and -5 , and from the abdominal aorta on Day 15 in Experiment 1 and on Day 29 (last day of the treatment period) and Day 56 (last day of the recovery period) in Experiment 2. On Day 15 in Experiment 1 and on Day 29 or Day 56 in Experiment 2, hematology examination and blood collection were performed under deep isoflurane inhalation anesthesia and fasted overnight.

Blood samples were treated with EDTA-2K. The following were analyzed using ADVIA 120 (Bayer Medical, Ltd., Tokyo, Japan): white blood cell (WBC), red blood cell (RBC), mean corpuscular volume (MCV), platelet count (PLT), reticulocyte percentage (RETIC), neutrophil percentage (NEUT), lymphocyte percentage (LYMP), monocyte percentage (MONO), eosinophil percentage (EOS), basophil percentage (BASO) and large unstained cell percentage (LUC) were measuring using a flow cytometry method. Hemoglobin concentration (HGB) was measured using a cyanmethohemoglobin method, hematocrit volume (HCT) was calculated from RBC and HGB, mean corpuscular hemoglobin content $(\mathrm{MCH})$ was calculated from RBC and HGB, and mean corpuscular hemoglobin concentration (MCHC) was calculated from RBC, HGB and MCV. Other blood samples were separated to serum $\left(1870 \times \mathrm{g}, 4^{\circ} \mathrm{C}, 10 \mathrm{~min}\right)$. The following were analyzed using an auto-analyzer 7170 (Hitachi Ltd., Tokyo, Japan): aspartate aminotransferase (AST), alanine aminotransferase (ALT), alkaline phosphatase (Al-P), lactate dehydrogenase (LDH), and creatine phosphokinase (CPK) were measuring using a Japan Society of Clinical Chemistry (JSCC) method. In addition, total cholesterol (TCho), triglyceride (TG), creatinine (CRN) and inorganic phosphorus (IP) were analyzed using an enzymatic method. Sodium $(\mathrm{Na})$, potassium $(\mathrm{K})$, and chloride $(\mathrm{Cl})$ were analyzed using ion-selective electrodes. Other analyses and the methods used include glucose (Glu) using hexokinase, total bilirubin (T-Bil) using alkaline azobilirubin, blood urea nitrogen (BUN) using urease/glutamate dehydrogenase, calcium $(\mathrm{Ca})$ using $O$-cresolphthalein complexone, total protein (TP) using biuret, albumin (Alb) using bromocresol green. The albumin/globulin ratio (A/ G) was calculated from the measured values of total protein and albumin.

\section{Necropsy}

At the end of the treatment period and the end of the recovery period (Experiment 2), the rats were euthanized by exsanguination from the abdominal aorta, proximal to the renal artery, under deep inhalation isoflurane anesthesia. Gross pathological observation was conducted for organs/tissues of whole body including the injection site (the abdominal area of the caudal vena cava central to the tip of the VAP catheter), the indwelling site of the VAP port (the subcutis of the lumbar region), and the indwelling site of the VAP catheter (from the abdominal region of the caudal vena cava distal to the tip of the catheter to the left common iliac vein and the left femoral vein) which were shown in Fig. 2.

\section{Histopathology}

In Experiment 1, lung, injection site, indwelling site of VAP catheter, indwelling site of VAP port and other organs/tissues with gross lesions were histopathologically examined. In Experiment 2, organs/tissues of the whole body were examined. Collected organs/tissues were fixed with $20 \%$ neutral buffered formalin solution, embedded with paraffin, sectioned at $3 \mu \mathrm{m}$, stained with hematoxylin and eosin (HE), and examined under light microscopy. In addition, for Experiment 2, the indwelling site of the VAP catheter and indwelling site of the VAP port was examined for gross findings but not examined histopathologically due to the similarity with the Experiment 1.

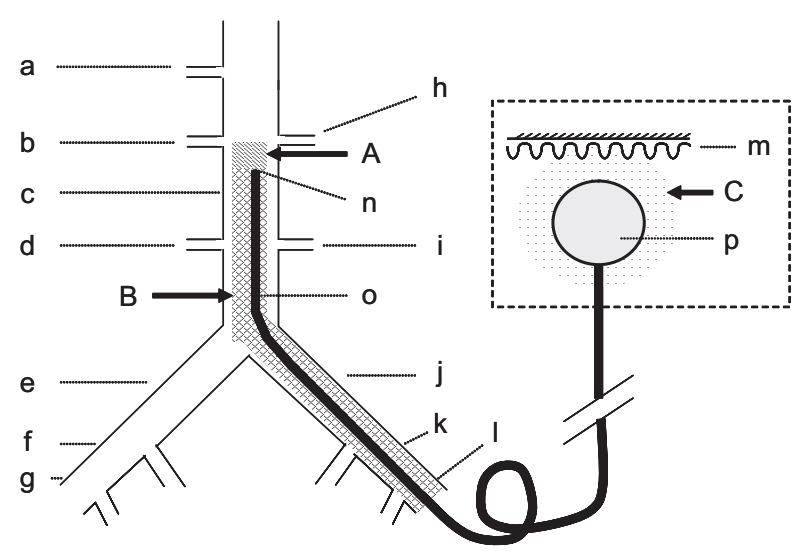

Fig. 2. Schema of injection site, catheter attachment site, and VAP indwelling site

A, injection site (the abdominal area of the caudal vena cava central to the tip of the VAP catheter; diagonal lined area); B, the indwelling site of the VAP catheter (from the abdominal region of the caudal vena cava distal to the tip of the catheter to the left common ilial vein and the left femoral vein; cross-hatched area); C, the indwelling site of the VAP port (the subcutis of the lumbar region; dotted area).

$\mathrm{a}$, hepatic vein; $\mathrm{b}$ and $\mathrm{h}$, renal veins (right and left); $\mathrm{c}$, caudal vena cava (abdominal region); $d$ and $i$, testicular or ovarian veins (right and left); e and j, common iliac veins (right and left); $f$ and $k$, external iliac veins (right and left); $g$ and 1 , femoral veins (right and left); $\mathrm{m}$, skin of the lumbar region; $\mathrm{n}$, end of the indwelling VAP catheter; o, VAP catheter; $p$, VAP port. 
Intravenous intermittent dose toxicity study using VAP in rats

\section{Statistical analysis}

Statistical analysis was performed using SAS preclinical package software (SAS version 5.0, SAS System 8.02; SAS Institute Japan Inc., Tokyo, Japan) for Experiment 1 and parametric data such as body weight, hematology and blood chemistry examination were analyzed. The Ftest was used to test for uniformity of variance (Significance level $\mathrm{p}<0.05$, Snedecor and Cochran, 1967). When homogeneity of variance was observed, the Student's ttest (Steel and Torrie, 1980) was conducted and, when not observed, the Welch's test (Snedecor and Cochran, 1967) was performed for significant differences between the VAPs group and the intact group. A value of $p<0.05$ was considered to be statistically significant.

\section{RESULTS}

\section{Operation results}

The number and percentage of animals excluded from both Experiments 1 and 2 and the detailed reasons for the exclusion are given in Table 1 . Approximately $80 \%$ of rats were successfully implanted with the VAP system and used for the studies. In Experiment 2, abnormalities included crust, loss of fur and reddish tear were noted in general condition. These changes were considered to spontaneous change due to the minimal number. Moreover, in order to prevent ophthalmologic abnormality observed in Experiment 2, chondroitin sodium sulfate as eye drop was used frequently during operation of VAPimplantation at the further study and then improved (data not shown).

Dragging of the hind legs was observed in some of animals at the end of the VAP validation study (Experiment 1), thought to be caused by the length of the VAP catheter becoming insufficient and interfering with the animal's movement following animal growth . Therefore, in further study (Experiment 2), the position of the VAP port was changed from the back of the neck to the lumbar region and dragging of the hind legs was not observed.

\section{Experiment 1 results}

\section{General condition and body weights}

No abnormalities were observed in general conditions in either sex during the treatment period. There were no changes in the VAPs group in body weight (Fig. 3) compared with the intact group.

\section{Hematology and blood chemistry examination}

Increases in RETIC (Table 2) were noted on Day 5 in females of the VAPs group in comparison with the
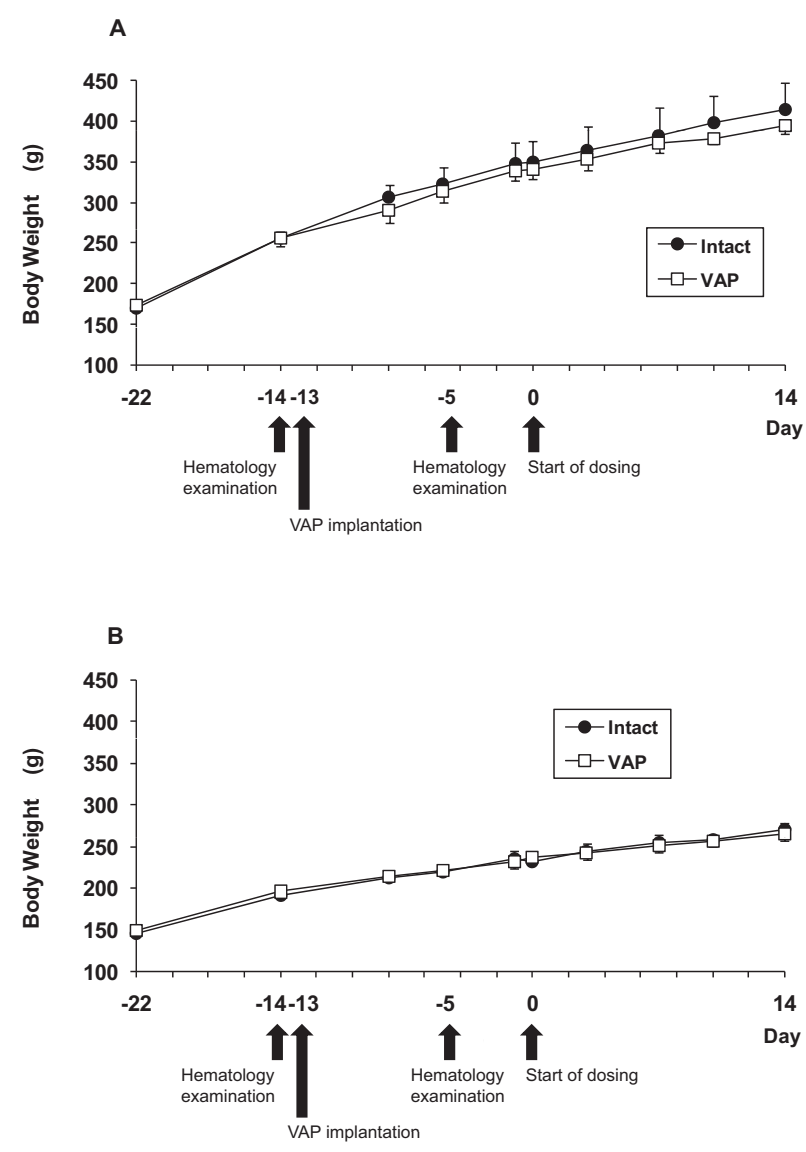

Fig. 3. Body weight changes in males (A) and females (B) in Experiment 1.

VAP implantation was performed on Day -13 . The weight of the VAP $(1.5 \mathrm{~g})$ is included in body weight. In the VAPs group, saline dosing was started on Day 0 ( 5 times/week, 2 weeks). Values are mean \pm S.D. of 6 animals.

intact group. This change was not observed at the end of the treatment period in the VAPs group. Increases in EOS were noted in both sexes of the VAPs group after VAP implantation and at the end of the treatment period. Increases in PLT were noted on Day 15 in females of the VAPs group. Increases in BASO in males of the VAPs group were thought to be non-treatment related because this change was noted before VAP implantation. No other changes were noted at any time points.

Blood chemistry examination was performed at the end of the treatment period (Table 3). In females of the VAPs group compared with the intact group, decreases in AST, T-Bil and K were noted. Even if statistically significant, these changes were slight in degree, sporadic and in 
J. Taketoh et al.

Table 2. Hematology examination results of Experiment 1

\begin{tabular}{|c|c|c|c|c|c|}
\hline \multirow[t]{2}{*}{ Item (unit) } & \multirow[b]{2}{*}{ Day } & \multicolumn{2}{|c|}{ Male } & \multicolumn{2}{|c|}{ Female } \\
\hline & & Intact & VAPs & Intact & VAPs \\
\hline \multicolumn{6}{|c|}{ WBC $\left(10^{3} / \mu \mathrm{l}\right)$} \\
\hline & Day -14 & $12.72 \pm 2.76$ & $12.02 \pm 1.62$ & $10.03 \pm 2.65$ & $8.18 \pm 3.29$ \\
\hline & Day -5 & $14.08 \pm 3.54$ & $12.57 \pm 2.28$ & $9.50 \pm 2.17$ & $9.92 \pm 2.86$ \\
\hline & Day 15 & $9.14 \pm 2.42$ & $8.78 \pm 3.92$ & $3.39 \pm 1.21$ & $3.83 \pm 1.79$ \\
\hline 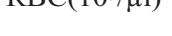 & Dav - 14 & $6.34 \pm 019$ & $651+0.25$ & $670 \pm 043$ & $666 \pm 025$ \\
\hline & Day -5 & $6.94 \pm 0.53$ & $6.94 \pm 0.35$ & $7.03 \pm 0.08$ & $6.93 \pm 0.24$ \\
\hline & Day 15 & $7.83 \pm 0.29$ & $7.85 \pm 0.22$ & $7.63 \pm 0.21$ & $7.53 \pm 0.40$ \\
\hline \multicolumn{6}{|l|}{$\operatorname{HGB}(\mathrm{g} / \mathrm{dl})$} \\
\hline & Day -14 & $13.8 \pm 0.6$ & $14.0 \pm 0.4$ & $14.1 \pm 0.6$ & $14.0 \pm 0.5$ \\
\hline & Day -5 & $14.6 \pm 1.2$ & $14.4 \pm 0.7$ & $14.4 \pm 0.3$ & $14.6 \pm 0.5$ \\
\hline & Day 15 & $15.3 \pm 0.6$ & $15.2 \pm 0.7$ & $15.1 \pm 0.5$ & $15.1 \pm 0.5$ \\
\hline HCT (\%) & Day -14 & $40.1 \pm 1.5$ & $40.5 \pm 1.5$ & $40.4 \pm 2.2$ & $40.5 \pm 1.3$ \\
\hline & Day -5 & $43.0 \pm 3.1$ & $42.5 \pm 2.1$ & $41.2 \pm 0.7$ & $42.0 \pm 1.7$ \\
\hline & Day 15 & $43.5 \pm 1.9$ & $43.1 \pm 2.1$ & $41.6 \pm 1.0$ & $42.0 \pm 1.5$ \\
\hline \multicolumn{6}{|l|}{ MCV (fl) } \\
\hline & Day -14 & $63.3 \pm 0.9$ & $62.2 \pm 1.8$ & $60.4 \pm 1.0$ & $60.9 \pm 1.9$ \\
\hline & Day -5 & $62.0 \pm 0.7$ & $61.2 \pm 1.6$ & $58.7 \pm 1.2$ & $60.5 \pm 1.7$ \\
\hline & Day 15 & $55.6 \pm 0.8$ & $54.9 \pm 2.1$ & $54.5 \pm 0.6$ & $55.9 \pm 1.4$ \\
\hline 101011 (Pg) & Day -14 & $21.8 \pm 0.3$ & $21.5 \pm 0.7$ & $21.1 \pm 0.6$ & $21.1 \pm 0.4$ \\
\hline & Day -5 & $21.1 \pm 0.2$ & $20.8 \pm 0.7$ & $20.5 \pm 0.4$ & $21.0 \pm 0.6$ \\
\hline & Day 15 & $19.5 \pm 0.3$ & $19.3 \pm 0.8$ & $19.7 \pm 0.4$ & $20.1 \pm 0.4$ \\
\hline \multicolumn{6}{|c|}{ MCHC $(\mathrm{g} / \mathrm{dl})$} \\
\hline & Day -14 & $34.4 \pm 0.3$ & $34.5 \pm 0.4$ & $34.9 \pm 0.7$ & $34.7 \pm 0.6$ \\
\hline & Day -5 & $34.1 \pm 0.4$ & $34.0 \pm 0.4$ & $35.0 \pm 0.4$ & $34.7 \pm 0.6$ \\
\hline & Day 15 & $35.1 \pm 0.3$ & $35.2 \pm 0.3$ & $36.2 \pm 0.7$ & $35.9 \pm 0.4$ \\
\hline \multicolumn{6}{|l|}{$\operatorname{PLT}\left(10^{3} / \mu 1\right)$} \\
\hline & Day -14 & $1,331 \pm 151$ & $1,290 \pm 68$ & $1,465 \pm 84$ & $1,392 \pm 126$ \\
\hline & Day -5 & $1,216 \pm 114$ & $1,321 \pm 258$ & $1,389 \pm 108$ & $1,480 \pm 92$ \\
\hline & Day 15 & $1,260 \pm 81$ & $1,257 \pm 86$ & $1,358 \pm 108$ & $1,168 \pm 120^{*}$ \\
\hline RETIC (\%) & Day -14 & $7.4 \pm 1.6$ & $6.2 \pm 0.5$ & $4.8 \pm 0.9$ & $4.9 \pm 0.7$ \\
\hline & Day -5 & $5.3 \pm 1.5$ & $6.8 \pm 0.7$ & $3.5 \pm 0.6$ & $5.7 \pm 0.4 * *$ \\
\hline & Day 15 & $2.3 \pm 0.4$ & $2.0 \pm 0.3$ & $1.6 \pm 0.2$ & $1.8 \pm 0.5$ \\
\hline \multicolumn{6}{|l|}{ NEUT (\%) } \\
\hline & Day -14 & $18.2 \pm 1.6$ & $18.5 \pm 3.2$ & $15.0 \pm 3.4$ & $20.3 \pm 9.4$ \\
\hline & Day -5 & $19.5 \pm 3.1$ & $19.1 \pm 5.5$ & $16.3 \pm 4.6$ & $13.8 \pm 3.6$ \\
\hline & Day 15 & $16.2 \pm 5.1$ & $24.0 \pm 11.7$ & $18.5 \pm 3.3$ & $23.4 \pm 6.6$ \\
\hline \multicolumn{2}{|l|}{ LYMPH(\%) } & $77.1 \pm 1.8$ & $77.1 \pm 3.6$ & $81.0 \pm 4.3$ & $75.1 \pm 10.1$ \\
\hline & Day -5 & $75.8 \pm 4.0$ & $75.8 \pm 5.7$ & $79.9 \pm 4.6$ & $81.1 \pm 4.3$ \\
\hline & Day 15 & $79.3 \pm 5.7$ & $70.5 \pm 11.9$ & $76.8 \pm 2.7$ & $70.9 \pm 6.7$ \\
\hline \multicolumn{4}{|l|}{ MONO(\%) } & $1.9 \pm 0.8$ & $2.5 \pm 0.9$ \\
\hline & Day -5 & $2.5 \pm 0.8$ & $2.4 \pm 0.8$ & $\begin{array}{l}1.9 \pm 0.0 \\
1.9 \pm 0.7\end{array}$ & $2.0 \pm 0.5$ \\
\hline & Day 15 & $2.3 \pm 0.5$ & $2.5 \pm 0.9$ & $2.3 \pm 1.0$ & $2.0 \pm 0.6$ \\
\hline \multicolumn{6}{|l|}{ EOS (\%) } \\
\hline & $\begin{array}{l}\text { Day }-14 \\
\text { Day }-5\end{array}$ & $1.2 \pm 0.5$ & $1.9 \pm 0.5^{* *}$ & $1.1 \pm 0.3$ & $2.1 \pm 1.4$ \\
\hline \multirow{4}{*}{ BASO (\%) } & Day 15 & $1.5 \pm 0.6$ & $2.2 \pm 1.2$ & $1.8 \pm 0.7$ & $3.3 \pm 0.6^{* *}$ \\
\hline & & & & & \\
\hline & Day -14 & $0.4 \pm 0.1$ & $\begin{array}{l}0.6 \pm 0.1^{* *} \\
0.5 \pm 0.2\end{array}$ & $\begin{array}{l}0.4 \pm 0.1 \\
0.4 \pm 0.1\end{array}$ & $\begin{array}{l}0.3 \pm 0.1 \\
0.5 \pm 0.3\end{array}$ \\
\hline & $\begin{array}{l}\text { Day }- \\
\text { Day } 15\end{array}$ & $\begin{array}{l}0.5 \pm 0.1 \\
0.4 \pm 0.1\end{array}$ & $0.5 \pm 0.1$ & $0.3 \pm 0.1$ & $0.3 \pm 0.1$ \\
\hline \multirow{3}{*}{ LUC (\%) } & Day -14 & $0.6 \pm 0.1$ & $0.5 \pm 0.2$ & $0.6 \pm 0.2$ & $0.6 \pm 0.1$ \\
\hline & Day -5 & $0.5 \pm 0.1$ & $0.5 \pm 0.1$ & $0.5 \pm 0.1$ & $0.6 \pm 0.2$ \\
\hline & Day 15 & $0.4 \pm 0.2$ & $0.3 \pm 0.1$ & $0.3 \pm 0.1$ & $0.3 \pm 0.1$ \\
\hline
\end{tabular}

Values are mean \pm S.D. of 6 animals.

Intact, non-treated/non VAP-implanted animal group; VAPs, VAP-implanted animal group; Day -14, before VAP implantation (in conscious animals); Day -5, after VAP implantation (in conscious animals); Day 15, last day of the treatment period (under isoflurane anesthesia after being fasted overnight).

$* \mathrm{p}<0.05 ; * \mathrm{p}<0.01$; significantly different from intact (Student's or Welch's t-test). 
Intravenous intermittent dose toxicity study using VAP in rats

Table 3. Blood chemistry results on Day 15 of Experiment 1

\begin{tabular}{|c|c|c|c|c|c|}
\hline \multirow[b]{2}{*}{ Item } & \multirow[b]{2}{*}{ Unit } & \multicolumn{2}{|c|}{ Male } & \multicolumn{2}{|c|}{ Female } \\
\hline & & Intact & VAPs & Intact & VAPs \\
\hline $\mathrm{TP}$ & $\mathrm{g} / \mathrm{dl}$ & $6.13 \pm 0.22$ & $6.03 \pm 0.08$ & $6.43 \pm 0.34$ & $6.59 \pm 0.16$ \\
\hline Alb & $\mathrm{g} / \mathrm{dl}$ & $13.81 \pm 0.16$ & $3.61 \pm 0.51$ & $4.15 \pm 0.13$ & $4.12 \pm 0.10$ \\
\hline $\mathrm{A} / \mathrm{G}$ & & $1.65 \pm 0.13$ & $1.57 \pm 0.42$ & $1.84 \pm 0.19$ & $1.67 \pm 0.13$ \\
\hline LDH & IU/1 & $96 \pm 30$ & $103 \pm 23$ & $77 \pm 27$ & $74 \pm 22$ \\
\hline AST & $\mathrm{IU} / 1$ & $81 \pm 15$ & $96 \pm 18$ & $110 \pm 14$ & $90 \pm 10^{*}$ \\
\hline ALT & $\mathrm{IU} / 1$ & $28 \pm 3$ & $33 \pm 6$ & $23 \pm 4$ & $23 \pm 4$ \\
\hline Al-P & IU/1 & $573 \pm 103$ & $542 \pm 138$ & $288 \pm 26$ & $314 \pm 33$ \\
\hline CPK & IU/1 & $139 \pm 24$ & $156 \pm 38$ & $93 \pm 35$ & $85 \pm 22$ \\
\hline T-Cho & $\mathrm{mg} / \mathrm{dl}$ & $56 \pm 4$ & $54 \pm 12$ & $60 \pm 12$ & $62 \pm 9$ \\
\hline TG & $\mathrm{mg} / \mathrm{dl}$ & $50 \pm 18$ & $39 \pm 9$ & $12 \pm 4$ & $8 \pm 3$ \\
\hline Glu & $\mathrm{mg} / \mathrm{dl}$ & $152 \pm 39$ & $129 \pm 19$ & $129 \pm 11$ & $126 \pm 9$ \\
\hline $\mathrm{Ca}$ & $\mathrm{mg} / \mathrm{dl}$ & $10.22 \pm 0.35$ & $10.09 \pm 0.37$ & $10.13 \pm 0.23$ & $10.26 \pm 0.32$ \\
\hline BUN & $\mathrm{mg} / \mathrm{dl}$ & $14.2 \pm 1.2$ & $15.9 \pm 1.2 *$ & $16.2 \pm 0.8$ & $15.2 \pm 2.8$ \\
\hline T-Bil & $\mathrm{mg} / \mathrm{dl}$ & $0.09 \pm 0.02$ & $0.08 \pm 0.01$ & $0.11 \pm 0.02$ & $0.09 \pm 0.01^{*}$ \\
\hline $\mathrm{CRN}$ & $\mathrm{mg} / \mathrm{dl}$ & $0.22 \pm 0.02$ & $0.24 \pm 0.03$ & $0.27 \pm 0.04$ & $0.25 \pm 0.02$ \\
\hline IP & $\mathrm{mg} / \mathrm{dl}$ & $7.14 \pm 0.41$ & $7.03 \pm 0.34$ & $6.26 \pm 0.61$ & $6.23 \pm 0.40$ \\
\hline $\mathrm{Na}$ & $\mathrm{mEq} / 1$ & $141.7 \pm 0.9$ & $142.7 \pm 1.0$ & $141.4 \pm 0.7$ & $141.7 \pm 0.9$ \\
\hline $\mathrm{K}$ & $\mathrm{mEq} / 1$ & $4.30 \pm 0.12$ & $4.25 \pm 0.28$ & $4.61 \pm 0.24$ & $4.19 \pm 0.15^{* *}$ \\
\hline $\mathrm{Cl}$ & $\mathrm{mEq} / 1$ & $103.4 \pm 1.2$ & $103.2 \pm 0.9$ & $105.2 \pm 1.9$ & $104.9 \pm 0.8$ \\
\hline
\end{tabular}

Values are mean \pm S.D. of 6 animals.

Intact, non-treated/non VAP-implanted animal group; VAPs, VAP-implanted animal group; Day 15, last day of the treatment period (under isoflurane anesthesia after being fasted overnight).

$* \mathrm{p}<0.05 ; * \mathrm{p}<0.01$; significantly different from intact (Student's or Welch's t-test).

the range of physiological variation.

\section{Necropsy and histopathology}

In necropsy and histopathology, no abnormalities were observed in the intact group. The macroscopic findings in the VAPs group from necropsy are shown in Table 4. In histopathology, proliferation of endothelium, inflammatory cell infiltration in blood vessel and granulation tissue in subcutis at indwelling site of VAP and VAP catheter were noted in almost VAP-implanted rats (Table 5 and Fig. 4). Moreover, in lung, perivascular inflammatory cell infiltration, interstitial pneumonitis, hypertrophy of tunica media in arteriola and hypertrophy in smooth muscle of alveolar duct were observed in all VAP-implanted rats (Fig. 5). In addition, one male have shown focal degeneration/necrosis of tubule in kidney (Fig. 5).

\section{Experiment 2 results}

Body weights (Table 6), hematology examination (Table 7), and blood chemistry examination (Table 8) for the control group, dosed saline only, are shown. No abnormities were observed in general conditions, and progressing body weight gain was noted in both sexes throughout the study. Hematology and blood chemistry examinations performed on Day 29 and Day 56, compared with in-house data (data not shown) and Charles River's laboratory data (Mary and Charles, 2006), showed almost all parameters were in or near the range of physiological change. Slightly increases in NEUT were noted in both sexes on both Days 29 and 56. And decreases in WBC were noted in females on Day 56. For both Experiments 1 and 2, macroscopic findings and histopathological findings were similar on both examination days (Tables 4 and 5). However, some findings such as osteoarthritis in femur bone were observed only in Experiment 2.

\section{DISCUSSION}

Continuous and intermittent intravenous infusion is important for toxicity studies in pre-clinical research. Although animal models for continuous infusion (i.e. daily 24-hr infusion) are now well established, they have both advantages and disadvantages. Recently, vascular access models are being well used because chronic intravenous administration via the tail vain in rat is sometimes difficult. Moreover, routine administration via an indwell- 
J. Taketoh et al.

Table 4. Macroscopic findings in VAP-implanted rats of Experiments 1 and 2

\begin{tabular}{|c|c|c|c|c|c|c|}
\hline \multirow[b]{3}{*}{ Location/Organ } & \multirow{2}{*}{\multicolumn{2}{|c|}{$\begin{array}{c}\text { Experiment } 1 \\
\text { (VAPs) }\end{array}$}} & \multicolumn{4}{|c|}{ Experiment 2} \\
\hline & & & \multicolumn{2}{|c|}{ Treatment period } & \multicolumn{2}{|c|}{ Recovery period } \\
\hline & Male & Female & Male & Female & Male & Female \\
\hline Findings & $\mathrm{n}=6$ & $\mathrm{n}=6$ & $\mathrm{n}=10$ & $\mathrm{n}=10$ & $\mathrm{n}=5$ & $\mathrm{n}=5$ \\
\hline \multicolumn{7}{|l|}{ Injection site } \\
\hline nodule, tunica intima & 2 & 0 & 2 & 3 & 0 & 1 \\
\hline clotting & 1 & 0 & 0 & 0 & 0 & 0 \\
\hline \multicolumn{7}{|l|}{ Indwelling site of VAP catheter ${ }^{b}$} \\
\hline nodule, tunica intima & 0 & 4 & 1 & 1 & 2 & 1 \\
\hline thickening, blood vessel & 2 & 1 & 0 & 0 & 0 & 0 \\
\hline encapsulation, VAP catheter & 3 & 1 & 8 & 5 & 4 & 3 \\
\hline \multicolumn{7}{|l|}{ Indwelling site of VAP portc } \\
\hline dark red area & 1 & 0 & 0 & 0 & 0 & 1 \\
\hline ulcer skin & 0 & 0 & 0 & 0 & 1 & 0 \\
\hline encapsulation, VAP port & 0 & 0 & 1 & 2 & 1 & 0 \\
\hline \multicolumn{7}{|l|}{ Medial iliac lymph node } \\
\hline large & 1 & 0 & 0 & 0 & 0 & 0 \\
\hline \multicolumn{7}{|l|}{ Hilar lymph node } \\
\hline large & 1 & 0 & 2 & 1 & 0 & 0 \\
\hline \multicolumn{7}{|l|}{ Lung } \\
\hline dark red area & 1 & 2 & 2 & 4 & 0 & 0 \\
\hline brown area & 0 & 1 & 3 & 2 & 0 & 0 \\
\hline white area & 0 & 0 & 1 & 0 & 0 & 0 \\
\hline \multicolumn{7}{|l|}{ Kidney } \\
\hline brown area & 1 & 0 & 3 & 0 & 0 & 0 \\
\hline recessed area & 0 & 0 & 0 & 0 & 1 & 0 \\
\hline \multicolumn{7}{|l|}{ Spleen } \\
\hline large & 1 & 0 & 0 & 1 & 0 & 0 \\
\hline \multicolumn{7}{|l|}{ Bone (femur) } \\
\hline white area, distal facies articularis, unilateral & 0 & 0 & 1 & 1 & 0 & 0 \\
\hline \multicolumn{7}{|l|}{ Knee joint } \\
\hline swelling, unilateral & 0 & 0 & 1 & 1 & 0 & 0 \\
\hline increased viscous articular fluid, unilateral & 0 & 0 & 1 & 0 & 0 & 0 \\
\hline
\end{tabular}

aThe abdominal area of the caudal vena cava central to the tip of catheter of the VAP.

${ }^{b}$ The abdominal area of the caudal vena cava distal to the tip of catheter of the VAP, the left common ilial vein and left femoral vein; cThe subcutis of the lumber region of port site of the VAP.

In Experiment 1, no abnormalities were observed in the intact group.

ing vascular catheter is being used for clinical patients in many cases such as chemotherapy or total parenteral nutrition (Charvát et al., 2006; Ang et al., 2000; Strum et al., 1986; Niederhuber et al., 1982). Some chemothera- peutic agents irritate and thus are inadequate for a peripheral venous approach and repeated access to a peripheral vein has the risk of leakage (Mare et al., 2003). Clinical patients have marked stress from repeated vein puncture 
Intravenous intermittent dose toxicity study using VAP in rats

Table 5. Histopathological findings for VAP-implanted rats of Experiments 1 and 2

\begin{tabular}{|c|c|c|c|c|c|c|}
\hline \multirow{3}{*}{$\begin{array}{c}\text { Location/Organ } \\
\text { Findings } \\
\end{array}$} & \multirow{2}{*}{\multicolumn{2}{|c|}{$\begin{array}{c}\text { Experiment } 1 \\
\text { (VAPs) }\end{array}$}} & \multicolumn{4}{|c|}{ Experiment 2} \\
\hline & & & \multicolumn{2}{|c|}{ Treatment period } & \multicolumn{2}{|c|}{ Recovery period } \\
\hline & $\begin{array}{l}\text { Male } \\
\mathrm{n}=6\end{array}$ & $\begin{array}{c}\text { Female } \\
\mathrm{n}=6\end{array}$ & $\begin{array}{c}\text { Male } \\
\mathrm{n}=10\end{array}$ & $\begin{array}{c}\text { Female } \\
n=10\end{array}$ & $\begin{array}{l}\text { Male } \\
\mathrm{n}=5\end{array}$ & $\begin{array}{c}\text { Female } \\
\mathrm{n}=5\end{array}$ \\
\hline \multicolumn{7}{|l|}{ Injection site } \\
\hline proliferation, endothelium & 5 & 6 & 9 & 10 & 1 & 5 \\
\hline inflammatory cells infiltration, blood vessel & 1 & 1 & 4 & 3 & 2 & 1 \\
\hline thrombus, blood vessel & 2 & 2 & 2 & 4 & 0 & 2 \\
\hline Indwelling site of VAP catheter ${ }^{b}$ & & & N.E. & N.E. & N.E. & N.E. \\
\hline proliferation, endothelium & 6 & 4 & & & & \\
\hline inflammatory cells infiltration, blood vessel & 1 & 1 & & & & \\
\hline thrombus & 4 & 2 & & & & \\
\hline granulation tissue & 2 & 0 & & & & \\
\hline Indwelling site of VAP port ${ }^{c}$ & & & N.E. & N.E. & N.E. & N.E. \\
\hline inflammatory cells infiltration, subcutis & 2 & 3 & & & & \\
\hline hemorrhage, subcutis & 2 & 0 & & & & \\
\hline granulation tissue, subcutis & 4 & 2 & & & & \\
\hline \multicolumn{7}{|l|}{ Medial iliac lymph node } \\
\hline increased plasma cells, sinus & 1 & 0 & 0 & 0 & 0 & 0 \\
\hline hemosiderin deposition, medulla & 2 & 3 & 0 & 0 & 0 & 0 \\
\hline \multicolumn{7}{|l|}{ Hilar lymph node } \\
\hline increased plasma cell, sinus & 1 & 0 & 2 & 1 & 0 & 0 \\
\hline \multicolumn{7}{|l|}{ 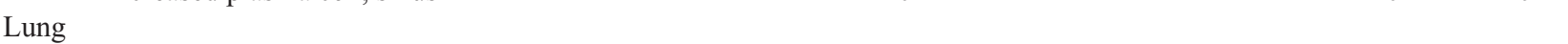 } \\
\hline inflammatory cells infiltration, perivascular & 6 & 6 & 10 & 10 & 5 & 5 \\
\hline interstitial pneumonitis & 6 & 6 & 7 & 10 & 5 & 5 \\
\hline hemorrhage, alveoli & 0 & 1 & 1 & 3 & 0 & 0 \\
\hline focal necrosis & 1 & 3 & 0 & 0 & 0 & 0 \\
\hline edema, alveoli/interstitium & 3 & 3 & 0 & 0 & 0 & 0 \\
\hline granuloma & 2 & 5 & 6 & 1 & 1 & 3 \\
\hline thrombus, arteriola & 1 & 1 & 0 & 3 & 0 & 1 \\
\hline hypertrophy, tunica media, arteriola & 6 & 6 & 10 & 10 & 5 & 5 \\
\hline hypertophy, smooth muscle, alveolar duct & 6 & 6 & 0 & 0 & 0 & 0 \\
\hline \multicolumn{7}{|l|}{ Kidney } \\
\hline tubulo-interstitial nephritis, focal & 0 & 0 & 4 & 0 & 1 & 0 \\
\hline degeneration/necrosis, tubule, focal & 1 & 0 & 0 & 0 & 0 & 0 \\
\hline \multicolumn{7}{|l|}{ Spleen } \\
\hline follicular hyperplasia & 1 & 0 & 0 & 1 & 0 & 0 \\
\hline \multicolumn{7}{|l|}{ Liver } \\
\hline inflammatory cell, Glission's sheath & 0 & 0 & 5 & 5 & 1 & 2 \\
\hline proliferation, bile duct & 0 & 0 & 2 & 0 & 1 & 3 \\
\hline granuloma & 0 & 0 & 7 & 6 & 2 & 3 \\
\hline Pancreas & N.E. & N.E. & & & & \\
\hline atrophy, acinar cell & & & 1 & 0 & 0 & 0 \\
\hline Bone (femur) & N.E. & N.E. & & & & \\
\hline osteoarthritis & & & 3 & 1 & 0 & 1 \\
\hline
\end{tabular}

aThe abdominal area of the caudal vena cava central to the tip of catheter of the VAP.

${ }^{b}$ The abdominal area of the caudal vena cava distal to the tip of catheter of the VAP, the left common ilial vein and left femoral vein; cThe subcutis of the lumber region of port site of the VAP.

N.E.: Not examined

and the risk of drug extravasation (Coates et al., 1983; Griffin et al., 1996). To avoid some of the problems in clinical patients, indwelling vascular catheters systems are commonly used and are especially useful for intermittent dosing. Hence, in drug evaluation in pre-clinical studies, an indwelling cannulation animal model would 


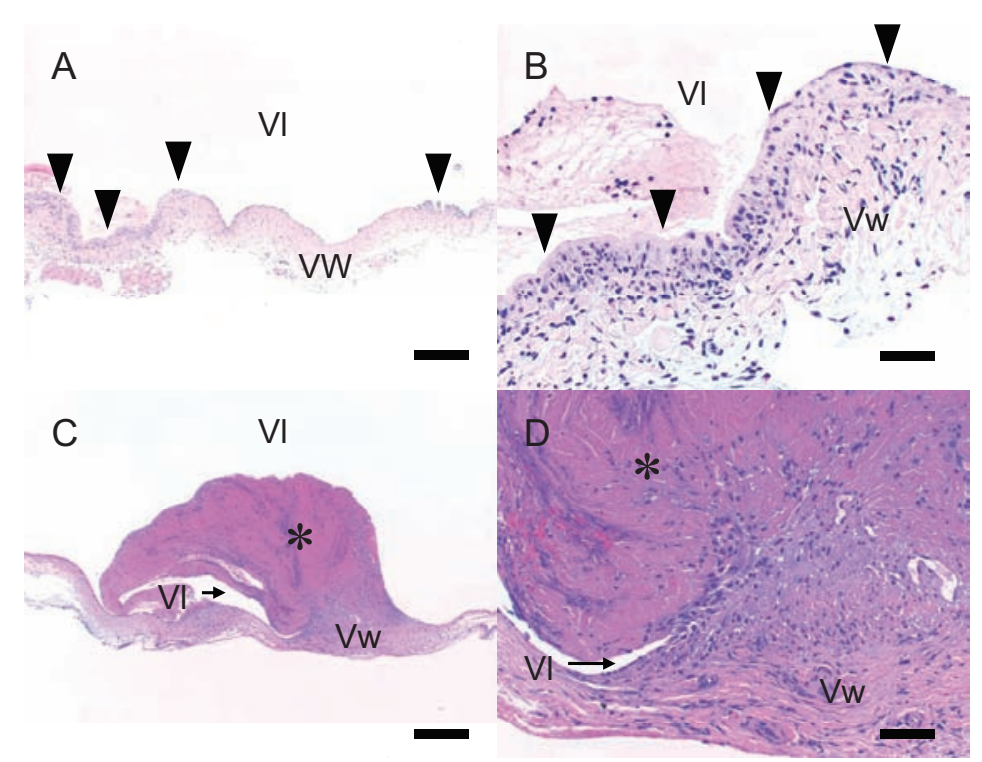

Fig. 4. Histopathological findings in injection site of VAP-implanted animals.

Histopathological changes in injection site (the abdominal area of caudal vena cava central to the tip of catheter of VAP) of VAP-implanted rats (panels A and B, slight lesion; panels C and D, moderate lesion) in Experiment 1. A, B; Proliferation of endothelium (arrow heads), inflammatory cells infiltration in blood vessel are observed. Panel B is a high magnification of panel A. C, D; Mural, organizing thrombus (asterisk) in blood vessel is noted. Panel D is a high magnification of panel C. This finding coincided with the change that was observed at necropsy such as the nodule of tunica intima in injection site. Abbreviations: Vl, vessel lumen; Vw, vessel wall. Hematoxylin and eosin staining. Bar: A, C = 250 $\mu \mathrm{m} ; \mathrm{B}, \mathrm{D}=50 \mu \mathrm{m}$.

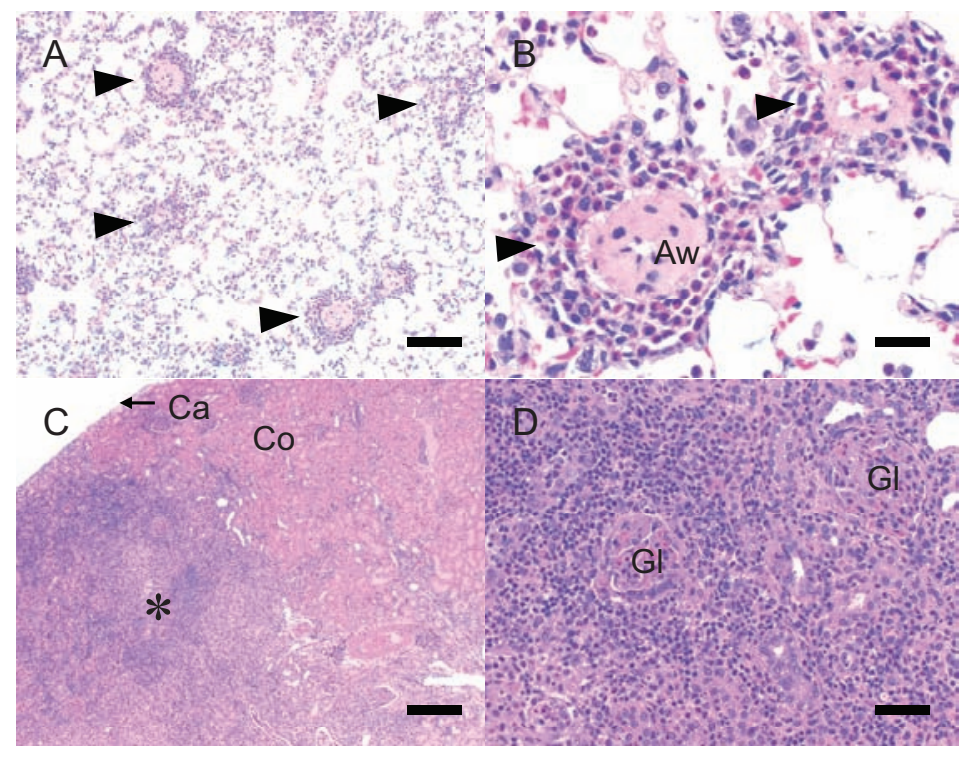

Fig. 5. Histopathological findings in lungs and kidneys of the VAP-implanted animals.

Histopathological changes in lungs (A, B) and kidneys (C, D) of VAP-implanted rats in Experiment 1. A, B; Perivascular inflammatory cell infiltration mainly composed of eosinophil (arrow heads), hypertrophy of tunica media of arteriola are observed. Panel B is a high magnification of panel A. C, D; Focal tubulo-interstitial nephritis is observed (asterisk). This finding coincided with the change that was observed at necropsy such as the brown area of kidney. Panel D is a high magnification of panel C. Abbreviations: Aw, arterial wall; Ca, Capsule; Co, cortex; Gl, glomerulus. Hematoxylin and eosin staining. Bar: $\mathrm{A}=100 \mu \mathrm{m} ; \mathrm{B}=25 \mu \mathrm{m} ; \mathrm{C}=250 \mu \mathrm{m} ; \mathrm{D}=50 \mu \mathrm{m}$. 
Intravenous intermittent dose toxicity study using VAP in rats

Table 6. Body weight change results of Experiment 2

\begin{tabular}{cccc}
\hline Day & $\begin{array}{c}\text { No. of } \\
\text { animals }\end{array}$ & $\begin{array}{c}\text { Male } \\
(\mathrm{g})\end{array}$ & $\begin{array}{c}\text { Female } \\
(\mathrm{g})\end{array}$ \\
\hline Day -21 & 15 & $177.3 \pm 4.0$ & $142.8 \pm 4.6$ \\
Day -16 & 15 & $231.8 \pm 4.6$ & $177.1 \pm 5.9$ \\
Day -9 & 15 & $275.2 \pm 9.3$ & $200.7 \pm 13.1$ \\
Day -6 & 15 & $294.4 \pm 10.2$ & $211.3 \pm 13.8$ \\
Day -1 & 15 & $323.6 \pm 13.3$ & $229.1 \pm 11.4$ \\
Day 0 & 15 & $330.6 \pm 14.7$ & $231.2 \pm 12.1$ \\
Day 7 & 15 & $359.5 \pm 21.5$ & $246.6 \pm 13.9$ \\
Day 14 & 15 & $393.0 \pm 25.6$ & $258.4 \pm 17.7$ \\
Day 21 & 15 & $417.8 \pm 30.1$ & $267.3 \pm 17.7$ \\
Day 28 & 15 & $436.6 \pm 32.1$ & $277.6 \pm 18.1$ \\
Day 35 & 5 & $447.4 \pm 18.6$ & $275.3 \pm 27.9$ \\
Day 42 & 5 & $468.5 \pm 19.3$ & $278.8 \pm 27.3$ \\
Day 49 & 5 & $484.0 \pm 21.4$ & $283.5 \pm 23.6$ \\
Day 55 & 5 & $492.6 \pm 22.1$ & $289.2 \pm 23.5$ \\
\hline
\end{tabular}

Weight of VAP $(1.5 \mathrm{~g})$ is included in body weight

more accurately estimate the human condition both pharmacokinetically and toxicokinetically. The aim of our first experiment reported here was to confirm the feasibility of using VAP-implanted rats for repeated dose toxicity studies.

The results of VAP implantation in both experiments were good, with an overall success rate of $80 \%$. Furthermore, death from deep anesthesia and ophthalmologic abnormalities in Experiment 1 were easily remedied by changing the anesthetic volume and the eye drop volume and thus the number of animals excluded from VAP implantation decreased. Moreover, in Experiment 1, some of animals showed dragging of the hind legs thought to be from pressure from the catheter as the animal grew in size but was remedied in Experiment 2 by implanting the VAP port in the lumbar area instead of the back of the neck. We concluded that the lumber region is more suitable for implantation of the VAP port. In hematology, increases in RETIC were noted in VAP-implanted females at 8 days after implantation (Day -5) but was considered to be a transient change resulting from the implantation procedure because this change had recovered by about 1 month after VAP implantation (Day 15). The VAP-implanted rats showed increases in EOS after implantation until the end of dosing. This change was possibly related to the histopathological findings observed in lung. Inflammation cell infiltration of the perivascular in lung mainly consist- ed of eosinophils. In histopathology, interstitial pneumonitis was noted in all VAP-implanted rats. The cannulation model of tail-cuff rats reportedly showed thrombi in the lung arteries and foreign body emboli in the alveolar septa (Jong et al., 2001). Furthermore, periarterial eosinophil infiltration, interstitial inflammation, and foreign body granulomas in lungs have been reported from intravenous infusions of large volumes of saline solutions in rats for 30 days (Morton et al., 1997). The possibility is raised that lung lesions by cannulation cause eosinophil infiltration and interstitial pneumonitis. In our experiment, no abnormality in general conditions or body weight was observed and so interstitial pneumonitis was not thought to be a severe condition in the evaluation of drug toxicity.

Almost all VAP-implanted rats showed implantationrelated changes at the indwelling site of the VAP port and catheter. The main observations were proliferation of endothelia and inflammatory cell infiltration of blood vessels. Comparing cannulation system in rats using a metal cuff with VAP-implantation, similar histopathological changes of inflammation of the vessel wall, intimal hyperplasia, and organized thrombi have been reported (Foley et al., 2002; Jong et al., 2001). These changes are considered reaction to a foreign body caused by the catheter itself. A recent report indicated that covalently-bound heparin coated catheter causes less pathologic damage to the catheter-related site (Foley et al., 2002) and thus possible to improve VAP-related adverse effects.

Blood chemistry results showed an increase in BUN in males, and decreases in AST, T-Bil and K were also noted. These changes were slight and near the physiological range value, and thought to have a minimal impact on the toxicological evaluation. For other abnormalities, one male showed degeneration and/or necrosis of focal tubule in kidney, follicular hyperplasia in spleen, and increased plasma cells in hilar lymph nodes. Also in this animal, high values of WBC and NEUT and slight decreases of body weight gain were noted (individual animal data not shown). We hypothesize that some subclinical infection had occurred in the animal because similar conditions have been described for infections associated with surgical techniques in rats. (Popp and Brennan, 1981; Bradfield et al., 1992).

Experiment 1 results indicate that VAP-implanted rats are well constructed for repeated dose toxicity studies even though this model has a background of alterations in the lung, kidney, spleen and VAP-related sites such as the injection site and the indwelling catheter site. However, above the fact, the effects of cannulation must be considered for the evaluation of a drug which has poten- 
J. Taketoh et al.

Table 7. Treatment period and recovery period hematology results of Experiment 2

\begin{tabular}{|c|c|c|c|c|c|}
\hline \multirow[b]{3}{*}{ Item } & \multirow[b]{3}{*}{ Unit } & \multicolumn{2}{|c|}{ Treatment period (Day 29)a } & \multicolumn{2}{|c|}{ Recovery period (Day 56)a } \\
\hline & & Male & Female & Male & Female \\
\hline & & $\mathrm{n}=10$ & $\mathrm{n}=10$ & $\mathrm{n}=5$ & $\mathrm{n}=5$ \\
\hline WBC & $10^{3} / \mu \mathrm{l}$ & $10.27 \pm 3.48$ & $6.41 \pm 2.45$ & $7.75 \pm 1.99$ & $2.66 \pm 0.55$ \\
\hline $\mathrm{RBC}$ & $10^{3} / \mu \mathrm{l}$ & $8.05 \pm 0.33$ & $7.73 \pm 0.31$ & $8.75 \pm .024$ & $7.93 \pm 0.41$ \\
\hline HGB & $\mathrm{g} / \mathrm{dl}$ & $15.2 \pm 0.7$ & $15.1 \pm 0.5$ & $15.7 \pm 0.3$ & $14.9 \pm 0.7$ \\
\hline HCT & $\%$ & $40.9 \pm 1.9$ & $39.9 \pm 1.1$ & $44.0 \pm 0.3$ & $40.7 \pm 1.9$ \\
\hline $\mathrm{MCV}$ & $\mathrm{fl}$ & $50.7 \pm 1.5$ & $51.6 \pm 1.7$ & $50.3 \pm 1.6$ & $51.2 \pm 1.0$ \\
\hline $\mathrm{MCH}$ & pg & $18.9 \pm 0.6$ & $19.6 \pm 0.7$ & $17.9 \pm 0.8$ & $18.7 \pm 0.5$ \\
\hline $\mathrm{MCHC}$ & $\mathrm{g} / \mathrm{dl}$ & $37.3 \pm 0.7$ & $37.9 \pm 0.6$ & $35.6 \pm 0.5$ & $36.6 \pm 0.4$ \\
\hline PLT & $10^{3} / \mathrm{ul}$ & $1184 \pm 133$ & $1053 \pm 123$ & $1063 \pm 122$ & $1173 \pm 170$ \\
\hline RETIC & $\%$ & $2.3 \pm 0.7$ & $2.0 \pm 0.4$ & $1.7 \pm 0.2$ & $2.2 \pm 0.6$ \\
\hline NEUT & $\%$ & $22.7 \pm 13.3$ & $17.4 \pm 7.4$ & $16.9 \pm 3.7$ & $21.1 \pm 8.5$ \\
\hline LYMPH & $\%$ & $72.1 \pm 13.2$ & $76.7 \pm 8.6$ & $78.1 \pm 3.8$ & $73.0 \pm 9.3$ \\
\hline MONO & $\%$ & $2.7 \pm 0.9$ & $2.8 \pm 1.1$ & $1.9 \pm 0.5$ & $2.0 \pm 0.3$ \\
\hline EOS & $\%$ & $1.6 \pm 0.8$ & $2.2 \pm 0.8$ & $2.2 \pm 0.6$ & $3.0 \pm 1.7$ \\
\hline BASO & $\%$ & $0.6 \pm 0.2$ & $0.7 \pm 0.2$ & $0.6 \pm 0.1$ & $0.5 \pm 0.4$ \\
\hline LUC & $\%$ & $0.3 \pm 0.2$ & $0.2 \pm 0.1$ & $0.4 \pm 0.1$ & $0.4 \pm 0.2$ \\
\hline
\end{tabular}

Values are mean \pm S.D. of 10 or 5 animals.

aFor hematology, animals were under isoflurane anesthesia after fasted overnight.

tial of inflammatory or hemorrhage in organs, especially, for lung (Kawagoe et al., 2008). Moreover, the compound of targeting to lymphohematopoietic system or kidney (House et al., 2007; Ito, 2000) may be paid attention under VAP-implanted rats study.

In Experiment 2, the VAP-implanted rat model was used for a long-term intermittent repeated dose toxicity study for evaluation some drug and we indicated control animal data in this report. This model of a 1-month intravenous administration followed by a 1-month recovery period complied with GLP. The VAP model was successfully maintained until the end of the recovery period (about 2 months after VAP implantation), confirmed by twice-weekly flushing. No abnormalities were observed in general conditions and normally progressing body weight gain was noted in both sexes. After operation, some animals suppressed body weight gains were observed (Table 1), however these changes were thought to be very slight. In Experiment 1, body weight after operation could not be evaluated because blood sampling for hematology was considered to be affected to body weight containing intact group. In pathological examination, changes similar to those in Experiment 1 such as proliferation of endothelium at the indwelling site of VAP catheter and inflam- matory cell infiltration of perivascular in lung and indwelling site of VAP port and VAP catheter were observed. However, observations in liver, knee joint and bone were noted only in Experiment 2 and were considered a result of a longer study period (1 month or 2 months) than for Experiment 1 (2 weeks). Hematology and blood chemistry at the end of the treatment period and at the end of the recovery period showed some changes such as increases in NEUT in both sexes and decreases in WBC in females. However, these changes were slight and thought to not hinder toxicological evaluation. In fact, in Experiment 2 , we conducted a repeated intravenous administration toxicity study using VAP-implanted rats and evaluated some drugs in this model, in which toxicity revealed a dose correlation. Moreover, this model enabled us to conduct a modified Irwin's test (Irwin, 1968), Irwin's test is commonly used for evaluate the effect of nervous system studying the behavioristics in safety pharmacology. This test needs for the free moving animals, therefore VAPimplanted animals are better adapted to the test.

We concluded that the usage of VAP in rats is useful for intravenous intermittent dose toxicity studies in rats and has advantages over other intravenous infusion methods commonly used in toxicity studies. With jacket 
Intravenous intermittent dose toxicity study using VAP in rats

Table 8. Treatment period and recovery period blood chemistry results of Experiment 2

\begin{tabular}{|c|c|c|c|c|c|}
\hline \multirow[b]{3}{*}{ Item } & \multirow[b]{3}{*}{ Unit } & \multicolumn{2}{|c|}{ Treatment period (Day 29) } & \multicolumn{2}{|c|}{ Recovery period (Day 56) } \\
\hline & & Male & Female & Male & Female \\
\hline & & $\mathrm{n}=10$ & $\mathrm{n}=10$ & $\mathrm{n}=5$ & $\mathrm{n}=5$ \\
\hline TP & $\mathrm{g} / \mathrm{dl}$ & $6.25 \pm 0.28$ & $6.62 \pm 0.16$ & $6.46 \pm 0.33$ & $6.76 \pm 0.35$ \\
\hline Alb & $\mathrm{g} / \mathrm{dl}$ & $3.52 \pm 0.29$ & $3.95 \pm 0.26$ & $3.70 \pm 0.24$ & $4.22 \pm 0.26$ \\
\hline $\mathrm{A} / \mathrm{G}$ & & $1.33 \pm 0.27$ & $1.15 \pm 0.29$ & $1.36 \pm 0.22$ & $1.68 \pm 0.21$ \\
\hline LDH & $\mathrm{IU} / 1$ & $98 \pm 35$ & $79 \pm 18$ & $104 \pm 34$ & $78 \pm 16$ \\
\hline AST & $\mathrm{IU} / 1$ & $90 \pm 15$ & $99 \pm 11$ & $93 \pm 16$ & $98 \pm 15$ \\
\hline ALT & $\mathrm{IU} / 1$ & $27 \pm 5$ & $23 \pm 6$ & $28 \pm 6$ & $25 \pm 8$ \\
\hline Al-P & $\mathrm{IU} / 1$ & $421 \pm 63$ & $272 \pm 80$ & $344 \pm 51$ & $182 \pm 49$ \\
\hline CPK & IU/1 & $144 \pm 30$ & $97 \pm 11$ & $95 \pm 31$ & $84 \pm 21$ \\
\hline T-Cho & $\mathrm{mg} / \mathrm{dl}$ & $55 \pm 8$ & $71 \pm 16$ & $48 \pm 12$ & $69 \pm 16$ \\
\hline TG & $\mathrm{mg} / \mathrm{dl}$ & $34 \pm 16$ & $11 \pm 6$ & $34 \pm 6$ & $10 \pm 4$ \\
\hline Glu & $\mathrm{mg} / \mathrm{dl}$ & $147 \pm 20$ & $132 \pm 14$ & $139 \pm 17$ & $144 \pm 17$ \\
\hline $\mathrm{Ca}$ & $\mathrm{mg} / \mathrm{dl}$ & $9.93 \pm 0.37$ & $10.15 \pm 0.31$ & $9.84 \pm 0.36$ & $9.81 \pm 0.21$ \\
\hline BUN & $\mathrm{mg} / \mathrm{dl}$ & $14.6 \pm 1.8$ & $16.3 \pm 2.1$ & $16.0 \pm 3.3$ & $16.3 \pm 2.1$ \\
\hline T-Bil & $\mathrm{mg} / \mathrm{dl}$ & $0.10 \pm 0.01$ & $0.11 \pm 0.02$ & $0.11 \pm 0.02$ & $0.10 \pm 0.03$ \\
\hline CRN & $\mathrm{mg} / \mathrm{dl}$ & $0.23 \pm 0.02$ & $0.27 \pm 0.04$ & $0.27 \pm 0.05$ & $0.29 \pm 0.03$ \\
\hline IP & $\mathrm{mg} / \mathrm{dl}$ & $7.05 \pm 0.37$ & $6.24 \pm 0.67$ & $6.51 \pm 0.20$ & $5.21 \pm 0.90$ \\
\hline $\mathrm{Na}$ & $\mathrm{mEq} / 1$ & $143.7 \pm 0.8$ & $142.5 \pm 0.7$ & $143.4 \pm 0.6$ & $141.6 \pm 0.5$ \\
\hline K & $\mathrm{mEq} / 1$ & $4.48 \pm 0.19$ & $4.29 \pm 0.31$ & $4.33 \pm 0.20$ & $4.14 \pm 0.35$ \\
\hline $\mathrm{Cl}$ & $\mathrm{mEq} / 1$ & $104.4 \pm 1.4$ & $104.0 \pm 0.9$ & $103.7 \pm 0.8$ & $105.4 \pm 0.4$ \\
\hline
\end{tabular}

Values are mean \pm S.D. of 10 or 5 animals.

${ }^{a}$ For blood chemistry examination, animals were under isoflurane anesthesia after fasted overnight.

or tail-cuff methods for continuous intravenous infusion, many devices (infusion pump, swivel and tether) are necessary and are costly. The use of VAP eliminates a permanent catheter exit point and the need for collars, jackets, tethers, and external catheters, allowing the animal to roam freely. The VAP system also has the advantage of allowing multiple housing of rodents (vs. the single housing required for tethered animals). However, VAP has the disadvantages of handling which requires generally two people, one holding the animal and the other performing injection. This model is also not suitable for continuous intravenous infusion such as total parenteral nutrition.

In summary, the VAP-implanted model has cannulation-specific changes such as proliferation of endothelium at the VAP-implanted site and inflammation cell infiltration of eosinophils of the perivascular in lung. The VAPimplanted model is considered useful for repeated and intermittent intravenous application of drugs over a period of 1 month or 2 months in rats. Moreover, it is expect- ed that progressive techniques, such as using a covalently-bound heparin coating catheter, would improve the study accuracy and better extrapolate to the human clinical condition.

\section{ACKNOWLEDGMENTS}

We thank Ms. Makiko Okada and Mr. Makoto Onohara for their excellent technical assistance in conducting the animal studies.

\section{REFERENCES}

Ang, P., Chia, K.H., Teoh, M.K. and Wong, K.K. (2000): Use of a peripherally implanted subcutaneous permanent central venous access device for chemotherapy : the Singapore General Hospital experience. Aust. NZ. J. Med., 30, 470-474.

Asanuma, K., Komatsu, S., Sakurai, T., Takai, R. and Chiba, S. (2006): Total parenteral nutrition using continuous intravenous infusion via the posterior vena cava in rats. J. Toxicol. Sci., 31, 
J. Taketoh et al.

139-147.

Bradfield, J.F., Schachtman, T.R., McLaughlin, R.M. and Steffen, E.K. (1992): Behavioral and physiologic effects of inapparent wound infection in rats. Lab. Anim. Sci., 42, 572-578.

Cave, D.A., Schoenmakers, A.C., van Wijk, H.J., Enninga, I.C. and van der Hoeven, J.C. (1995): Continuous intravenous infusion in the unrestrained rat-procedures and results. Hum. Exp. Toxicol., 14, 192-200.

Charvát, J., Linke, Z., Horáèková, M. and Prausová, J. (2006): Implantation of central venous ports with catheter insertion via the right internal jugular vein in oncology patients: single center experience. Supportive Care in Cancer, 14, 1162-1165.

Coates, A., Abraham, S., Kaye, S.B., Sowerbutts, T., Frewin, C., Fox, R.M. and Tattersall, M.H. (1983): On the receiving end-patient perception of the side-effects of cancer chemotherapy. Eur. J. Cancer Clin. Oncol., 19, 203-208.

Foley, P.L., Barthel, C.H. and Brausa, H.R. (2002): Effect of covalently bound heparin coating on patency and biocompatibility of long-term indwelling catheters in the rat jugular vein. Comp. Med., 52, 243-248.

Garner, D. and Laks, M.M. (1985): New implanted chronic catheter device for determining blood pressure and cardiac output in conscious dog. Am. J. Physiol., 249, 681-684.

Garner, D., McGivern, R., Jagels, G. and Laks, M.M. (1988): A new method for direct measurement of systolic and diastolic pressures in conscious rats using Vascular-Access-Ports. Lab. Anim. Sci., 38, 205-207.

Gebhardt, J.H., Hinrichs, C., Fändrich, F., Schröder, J. and Bautz, A. (1997): Technical and surgical aspects of continuous vascular access in freely moving small animals. J. Lab. Clin. Med., 130, 421-426.

Griffin, A.M., Butow, P.N., Coates, A.S., Childs, A.M., Ellis, P.M., Dunn, S.M. and Tattersall, M.H. (1996): On the receiving end. V: Patient perceptions of the side effects of cancer chemotherapy in 1993. Ann. Oncol., 7, 189-195.

Groman, E.V. and Reinhardt, C.P. (2004): Method to quantify tail vein injection technique in small animals. Contemp. Top Lab. Anim. Sci., 43, 35-38.

House, A.A., Silva, O.S. and Ronco, C. (2007): Anti-inflammatory drugs and the kidney. Int. J. Artif. Organs, 30, 1042-1046

Irwin, S. (1968): Comprehensive observational assessment: Ia. A systematic, quantitative procedure for assessing the behavioral and physiologic state of the mouse. Psychopharmacologia, 13, 222-257.

Ito, N. (2000): Toxicological Histopathology. The Japanese Society of Toxicologic Pathology, Tokyo.

Jong, W.H., Timmerman, A. and Raaij, M.T. (2001): Long-term cannulation of the vena cava of rats for blood sampling: local and systemic effects observed by histopathology after six weeks of cannulation. Lab. Anim., 35, 243-248.

Kaufman, S. (1980): Chronic, nonocclusive, and maintenance-free central venous cannula in the rat. Am. J. Physiol., 239, 123-125.

Kawagoe, M., Ishikawa, K., Wang, S.C., Yoshikawa, K., Arany, S., Zhou, X.P., Wang, J.S., Ueno, Y., Koizumi, Y., Kameda, T.,
Koyota, S. and Sugiyama, T. (2008): Acute effects on the lung and the liver of oral administration of cerium chloride on adult, neonatal and fetal mice. J. Trace Elem. Med. Biol., 22, 59-65.

Mare, M., Maisano, R., Caristi, N., Adamo, V., Altavilla, G., Carboni, R., Munaò, S. and La Torre, F. (2003): Venous damage prevention by defibrotide in vinorelbine-treated patients. Support Care Cancer, 11, 593-596.

Mary, L.A. and Charles, B. (2006); Clinical Laboratory Parameters for $\mathrm{Crl}: \mathrm{CD}(\mathrm{SD})$ Rats. Charles River Laboratories.

Morton, D., Safron, J.A., Glosson, J., Rice, D.W., Wilson, D.M. and White, R.D. (1997): Histologic lesions associated with intravenous infusions of large volumes of isotonic saline solution in rats for 30 days. Toxicol. Pathol., 25, 390-394.

Niederhuber, J.E., Ensminger, W., Gyves, J.W., Liepman, M., Doan, K. and Cozzi, E. (1982): Totally implanted venous and arterial access system to replace external catheters in cancer treatment. Surgery, 92, 706-712.

Oliver, L., Camelia, N., Jean-Francois, L.B. and Roy, F. (1997): Corneal damage following continuous infusion in rats. Advances in ocular toxicology (Green, ed.), pp. 55-62, Plenum Press, New York.

Perry-Clark, L.M. and Meunier, L.D. (1991): Vascular access ports for chronic serial infusion and blood sampling in New Zealand white rabbits. Lab. Anim. Sci., 41, 495-497

Popp, M.B. and Brennan, M.F. (1981): Long-term vascular access in the rat: importance of asepsis. Am. J. Physiol., 241, 606-612.

Snedecor, G..W. and Cochran, W.G. (1967): In Statistical Methods: 6th ed. The Iowa State University Press Ames, Iowa.

Steel, R.G.D. and Torrie, J.H. (1980): In Principles and Procedures of Statistics, 2nd ed. McGraw Hill Book Company, New York.

Strum, S., McDermed, J., Korn, A. and Joseph, C. (1986): Improved methods for venous access: the Port-A-Cath, a totally implanted catheter system. J. Clin. Oncol., 4, 596-603.

Tesche, S., Sagowski, C., Zywietz, F., Jenicke, L., Bohuslavizki, K.H. and Metternich, F.U. (2002): Multiple application of drugs in rats - A new port system. Onkologie, 25, 178-180.

Wachtman, L.M., Browning, M.D., Bedja, D., Pin, S. and Gabrielson, K.L. (2006): Validation of the use of long-term indwelling jugular catheters in a rat model of cardiotoxicity. J. Am. Assoc. Lab. Anim. Sci., 45, 55-64.

Wijk, H., Dick, A., Greenough, R.J., Oshodi, R.O. and Robb, D. (2000): Continuous intravenous infusion in athymic (nude) rats: an animal model for evaluating the efficacy of anti-cancer agents. Lab. Anim., 34, 63-69.

Wit, M., Raabe, A., Tuinmann, G. and Hossfeld, D.K. (2001): Implantable device for intravenous drug delivery in the rat. Lab. Anim., 35, 321-324.

Wojnicki, F.H., Bacher, J.D. and Glowa, J.R. (1994): Use of subcutaneous vascular access ports in rhesus monkeys. Lab. Anim. Sci., 44, 491-494.

Yang, J., Maarek, J.M. and Holschneider, D.P. (2005): In vivo quantitative assessment of catheter patency in rats. Lab. Anim., 39, 259-268. 